\title{
Acute pyogenic discitis in a degenerative intervertebral disc in an adult
}

This article was published in the following Dove Press journal:

International Medical Case Reports Journal

2 August 2010

Number of times this article has been viewed

\section{Masamitsu Tanaka ${ }^{1,2}$ \\ Hiroshi Shimizu ${ }^{2}$ \\ Yoshiyuki Yato' \\ Takashi Asazuma' \\ Koichi Nemoto'}

'Department of Orthopedic Surgery, National Defense Medical College, Tokorozawa, Saitama; ${ }^{2}$ Department of Orthopedic Surgery, Self Defense Force Fukuoka Hospital, Kasuga, Fukuoka, Japan
Correspondence: Masamitsu Tanaka Department of Orthopedic Surgery, National Defense Medical College, 3-2 Namiki, Tokorozawa, Saitama 359-85I3, Japan

Tel +81429951663

Fax +8I 429965208

Email dr21046@ndmc.ac.jp
Abstract: A 35-year-old male who had been receiving conservative treatment for L4 isthmic spondylolisthesis suffered from pyogenic spondylodiscitis in the degenerative L4/L5 intervertebral disc space, which could be identified by comparison with previous images. Symptoms improved with conservative antibiotic treatment. Neovascularization may occur in the annulus fibrosus of a degenerative intervertebral disc, which may increase the risk of hematogenous infection, leading to "discitis" even in adults.

Keywords: spondylodiscitis, spondylitis, discitis, isthmic spondylolisthesis, spondylolysis, intervertebral disc degeneration

\section{Introduction}

In many cases of pyogenic spondylodiscitis, infection occurs primarily in the anterior corner of the vertebral body, and the infected lesion gradually extends to the adjacent vertebra via an intervertebral disc. However, we often encounter cases in which infectious changes are seen only in an intervertebral disc space without bone destruction or spur formation in the anterior corner of the vertebral body. Although an intervertebral disc is avascular in adults, such cases seem to be similar to "discitis" in infants. In these cases, the primary focus of the infection may not be an anterior corner of the vertebral body but in an intervertebral disc itself. Various factors, such as intervertebral disc degeneration, may be involved in the occurrence of hematogenous infection directly to an intervertebral disc in adults. However, the mechanisms are unclear.

We encountered a patient with pyogenic spondylodiscitis in the slipped intervertebral disc space of lumbar isthmic spondylolisthesis. We were able to confirm by comparison with previous images obtained from the patient that lumbar isthmic spondylolisthesis preceded pyogenic spondylodiscitis and that pyogenic spondylodiscitis developed only in the degenerative disc space. The relationship between degeneration of an intervertebral disc and hematogenous infection with focus on neovascularization into the annulus fibrosus of the degenerated disc is discussed.

\section{Case report}

A 35-year-old man, an orthopedic surgeon, had experienced low back pain since the age of 17 years. He was diagnosed with L4 lumbar isthmic spondylolisthesis at the age of 28 years and had been receiving conservative treatment with periodic plain $\mathrm{x}$-ray and magnetic resonance imaging (MRI) examinations (Figure 1). There was no particular past or familial medical history. In January 2006, he felt severe low back pain and took an oral nonsteroidal anti-inflammatory agent of his own accord, but the 


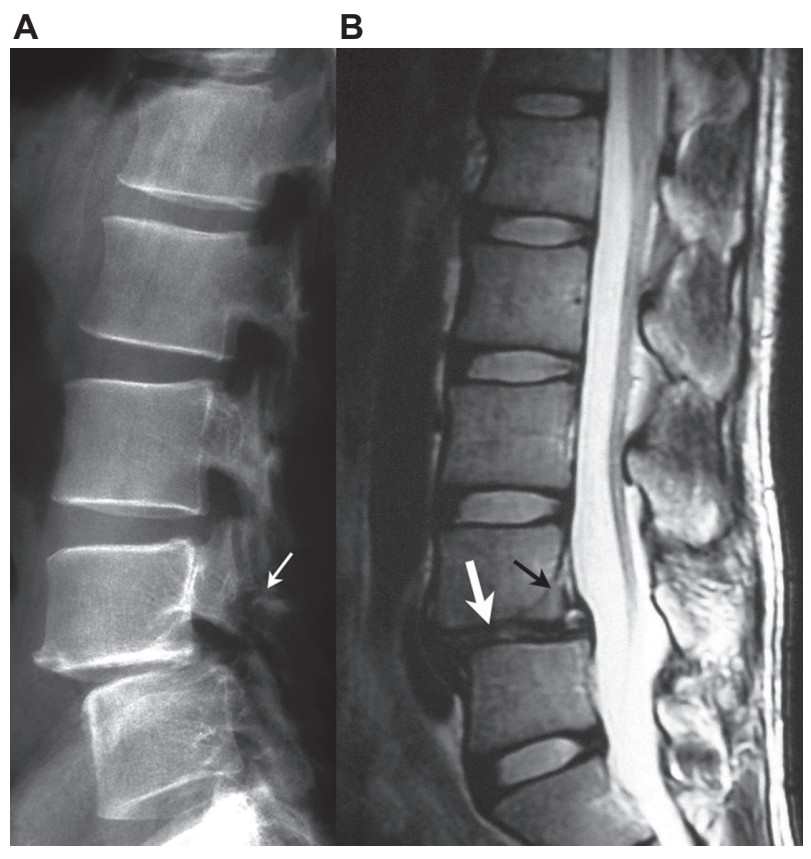

Figure I Images 7 months before the onset of pyogenic spondylodiscitis. A) Plain x-ray. Separation of the L4 vertebral arch (small white arrow) and L4/L5 listhesis were noted. B) Plain T2-weighted MRI. The L4/L5 intervertebral disc was degenerated and the height of the intervertebral disc space was decreased (thick white arrow). Separation of ring apophysis of the L 4 vertebral body was noted (small black arrow). pain aggravated the following day. He was admitted to our hospital for close examination and treatment.

His body temperature was $38.5^{\circ} \mathrm{C}$ and he had severe continuous pain over the entire lumbar region on admission, but no apparent neurologic disturbance was detected. Blood examination showed that his white blood cell (WBC) count and C-reactive protein (CRP) had risen to high levels $(8,500 / \mu \mathrm{L}$ and $3.72 \mathrm{mg} / \mathrm{dL}$, respectively). Plain lumbar x-ray and MRI were performed (Figure 2) and the images were compared with those acquired 7 months previously. Although osteosclerosis of the vertebral body adjacent to the L4/L5 intervertebral disc space was noted on X-ray images, height and slip amount of the L4/L5 disc space was not changed, and no apparent bone destruction or spur formation was seen in the anterior corner of the vertebral bodies. An apparent change in the signal intensity of the L4/L5 disc space was noted on T2-weighted MRI, and the vertebrae adjacent to the L4/L5 disc space were enhanced on gadolinium-enhanced fat-suppressed T1-weighted MRI.

Based on these findings, L4/L5 intervertebral pyogenic spondylodiscitis was diagnosed, and conservative treatment with antibiotics by drip infusion was initiated.
A

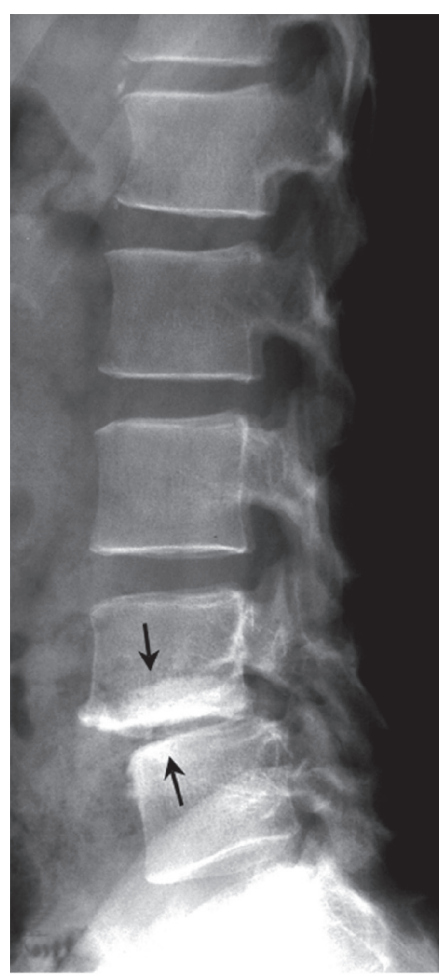

B

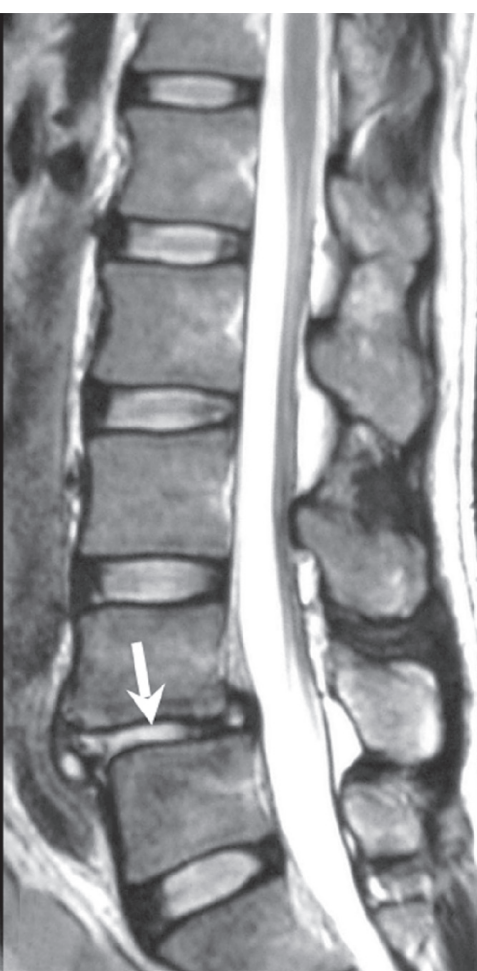

C

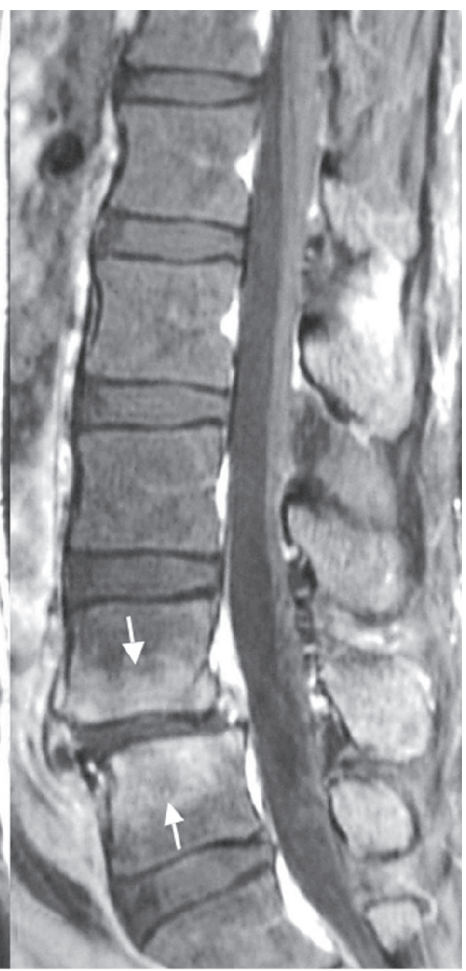

Figure 2 Images on admission. A) Plain x-ray. Although osteosclerosis of the L4 and L5 vertebral bodies was noted (small black arrow), no apparent bone destruction or spur formation was seen in the anterior corner of the vertebral bodies. B) Plain T2-weighted MRI. Signal intensity of the L4/L5 intervertebral disc had apparently changed in comparison with that shown in Figure I (thick white arrow). C) Gadolinium-enhanced fat-suppressed TI-weighted MRI. The L4 and L5 vertebral bodies adjacent to the L4/L5 intervertebral disc space were enhanced with gadolinium (small white arrow). 
Table I Time courses of WBC count, neutrophil count, CRP, and ESR

\begin{tabular}{llllllll}
\hline $\begin{array}{l}\text { Day of } \\
\text { treatment }\end{array}$ & $\mathbf{2}$ & $\mathbf{4}$ & $\mathbf{6}$ & $\mathbf{9}$ & $\mathbf{1 9}$ & $\mathbf{4 0}$ & $\mathbf{5 4}$ \\
\hline WBC $(/ \mu \mathrm{L})$ & 8,500 & $1 \mathrm{I}, 400$ & 8,800 & 8,100 & 7,800 & 5,600 & 4,700 \\
$\begin{array}{l}\text { Neutrophil } \\
\text { rate }(\%)\end{array}$ & & 81.5 & 78.2 & 77.8 & 73 & 64.6 & 60.3 \\
$\mathrm{CRP}(\mathrm{mg} / \mathrm{dL})$ & 3.72 & 6.71 & 12.41 & 3.49 & 0.41 & 0.12 & 0.05 \\
ESR $(\mathrm{mm} / \mathrm{hour})$ & & 78 & & 113 & 72 & 25 & 16 \\
\hline
\end{tabular}

Abbreviations: ESR, erythrocyte sedimentation rate; CRP, C-reactive protein; WBC, white blood cell count.

Cefazolin sodium was administered intravenously for 40 days ( $4 \mathrm{~g}$ /day for 7 days and $2 \mathrm{~g} /$ day for 33 days), followed by oral cefaclor at $750 \mathrm{mg}$ /day for about 3 months. A venous blood culture test performed on the night of admission was negative. WBC count, neutrophil rate, CRP, and erythrocyte sedimentation rate reached maximum levels on the fourth, sixth, and ninth days of treatment, and then gradually decreased (see Table 1). The low back pain gradually improved, and the patient was discharged after 2 months and was able to walk with a semirigid corset attachment.
On plain lumbar x-ray taken 6 months after treatment, the $\mathrm{L} 4 / \mathrm{L} 5$ disc space was lost and instability present before the occurrence of pyogenic spondylodiscitis was resolved. The marked signal intensity of the L4/L5 intervertebral disc space on MRI had disappeared, but enhancement of the adjacent vertebral bodies remained (Figure 3). There has been no recurrence of low back pain as of about 4 years after treatment and the patient has returned to work as an orthopedic surgeon.

\section{Discussion}

To our knowledge, there have been only 4 reports of lumbar isthmic spondylolisthesis and pyogenic spondylodiscitis occurrence in the same intervertebral region, ${ }^{1-4}$ although the actual frequency of occurrence is unclear. The reasons for infection of the listhetic intervertebral space were not discussed in those reports because all cases were primarily examined at the onset of pyogenic spondylodiscitis and, therefore, no images preceding pyogenic spondylodiscitis were available. In contrast, our case provided evidence based on comparison with previous images that lumbar isthmic spondylolisthesis and intervertebral disc degeneration preceded
A

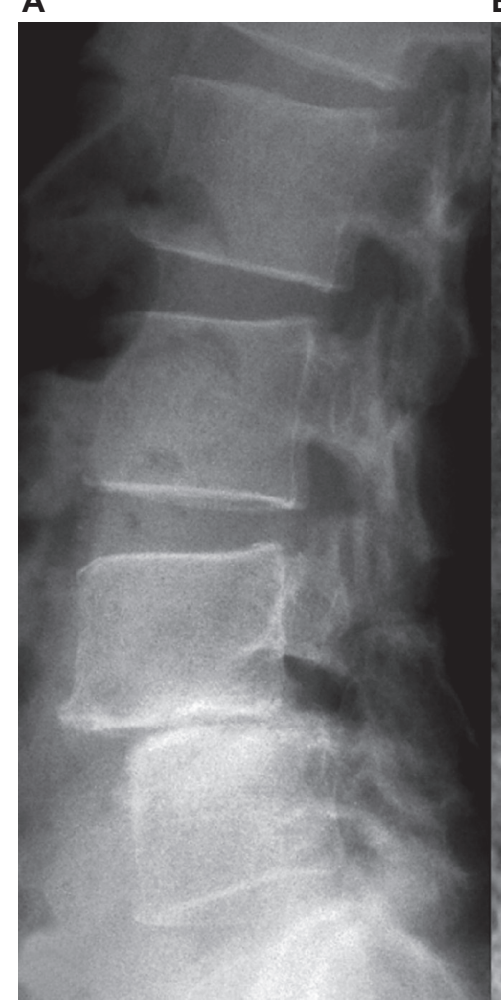

$B$

Bary

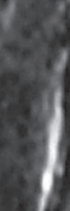

$\ln _{0}$

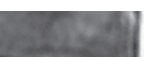

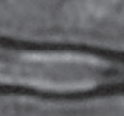
$\sin$

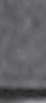
1 $2 \mathrm{~s}$ 1.

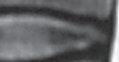

(10)

C

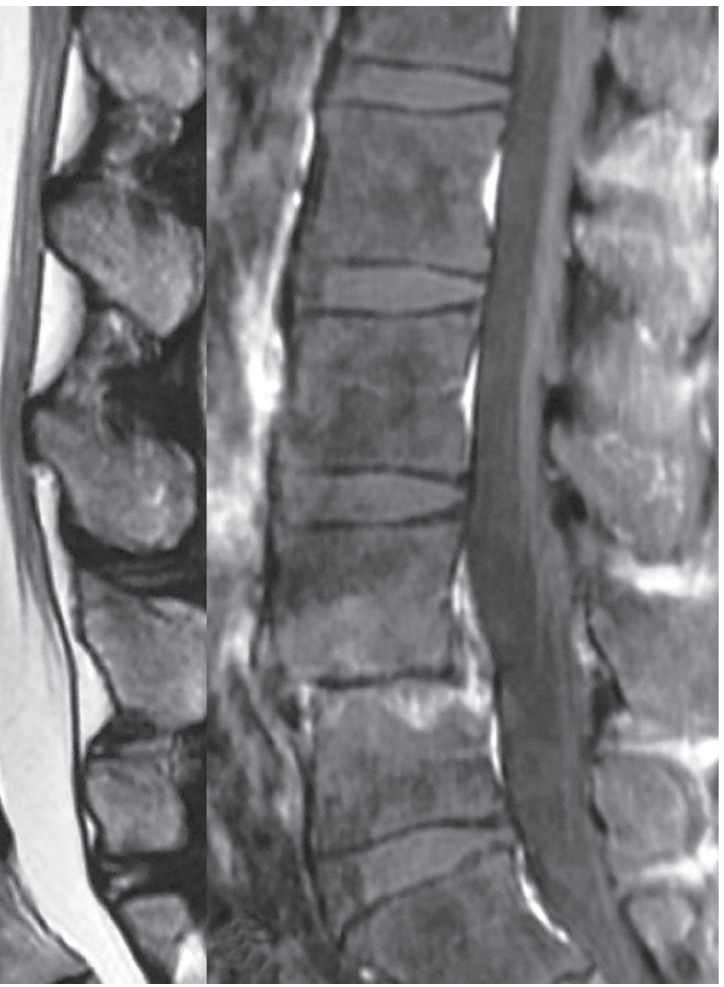

Figure 3 Images 6 months after treatment. A) Plain x-ray. The L4/L5 intervertebral space was lost. B) Plain T2-weighted MRI. The high signal intensity of the L4/L5 intervertebral disc was resolved. C) Gadolinium-enhanced fat-suppressed TI-weighted MRI. Enhancement in the adjacent vertebral bodies remained. 
pyogenic spondylodiscitis and that pyogenic spondylodiscitis occurred in the degenerative disc space.

The patient was young and had no apparent risk of infection. Furthermore, infection occurred only in the degenerative intervertebral disc space. These facts suggest that degeneration of an intervertebral disc might be related to susceptibility to microbial infection.

Since there is circulation in the annulus fibrosus of the intervertebral disc in infants, ${ }^{5-7}$ the initial stage of disc space infection in infants is considered to be "discitis" ${ }^{8-10}$ In adults, in contrast, the intervertebral artery terminates in the cancellous bone proximal to the vertebral end plate and thus the intervertebral discs are avascular in nature. Thus, the initial stage of disc space infection in adults is considered to be "spondylitis" or "vertebral osteomyelitis".,10-12 However, in some studies, high expression levels of vascularizationrelated growth factors were noted in the annulus fibrosus of degenerative discs with progression of vascularization. ${ }^{13-15}$ These observations suggest that the annulus fibrosus may occasionally be the primary site of hematogenous infection, ${ }^{16}$ and that the risk of hematogenous infection increases with progression of disc degeneration. Thus, not only "spondylitis" or "vertebral osteomyelitis", but also "discitis", may occur in an adult who has disc space degeneration. Although results of some retrospective clinical studies ${ }^{17,18}$ suggesting a correlation between disc degeneration and infection might support these hypotheses, many aspects still remain unclear and further investigation is necessary.

The patient was an orthopedic surgeon, and therefore the subjective symptoms and the clinical progress described above were considered to be objective and accurate. The patient was informed that data and photographs from the case would be submitted for publication, and his consent was given.

\section{Disclosure}

The authors report no conflict of interest in this work.

\section{References}

1. Smorgick Y, Floman Y, Anekstein Y, Shitrit R, Copeliovitch L, Mirovsky Y. Discitis and isthmic spondylolisthesis: A case report. J Pediatr Orthop B. 2008;17:39-41.

2. Guglielmino A, Sorbello M, Murabito P, et al. A case of lumbar sciatica in a patient with spondylolysis and spondylolysthesis and underlying misdiagnosed brucellar discitis. Minerva Anestesiol. 2007;73:307-312.

3. Nagashima H, Morio Y, Nishi T, Hagino H, Teshima R. Spontaneous fusion of isthmic spondylolisthesis after discitis: A case report. Clin Orthop Relat Res. 2002;403:104-107.

4. Wynne AT, Southgate GW. Discitis causing spondylolisthesis. A case report. Spine. 1986;11:970-972.

5. Rudert M, Tillmann B. Lymph and blood supply of the human intervertebral disc. Cadaver study of correlations to discitis. Acta Orthop Scand. 1993;64:37-40.

6. Whalen JL, Parke WW, Mazur JM, Stauffer ES. The intrinsic vasculature of developing vertebral end plates and its nutritive significance to the intervertebral discs. J Pediatr Orthop. 1985;5:403-410.

7. Roberts S, Evans H, Trivedi J, Menage J. Histology and pathology of the human intervertebral disc. J Bone Joint Surg Am. 2006;88 (Suppl 2):10-14.

8. Scoles PV, Quinn TP. Intervertebral discitis in children and adolescents. Clin Orthop Relat Res. 1982;162:31-36.

9. Song KS, Ogden JA, Ganey T, Guidera KJ. Contiguous discitis and osteomyelitis in children. J Pediatr Orthop. 1997;17:470-477.

10. Wiley AM, Trueta J. The vascular anatomy of the spine and its relationship to pyogenic vertebral osteomyelitis. J Bone Joint Surg Br. 1959; 41B:796-809.

11. Ratcliffe JF. Anatomic basis for the pathogenesis and radiologic features of vertebral osteomyelitis and its differentiation from childhood discitis. A microarteriographic investigation. Acta Radiol Diagn (Stockh). 1985;26:137-143

12. Ratcliffe JF. The arterial anatomy of the adult human lumbar vertebral body: A microarteriographic study. J Anat. 1980;131:57-79.

13. Ali R, Maitre CL, Richardson SM, Hoyland JA, Freemont AJ. Connective tissue growth factor expression in human intervertebral disc: Implications for angiogenesis in intervertebral disc degeneration. Biotech Histochem. 2008;83:239-245.

14. Boos N, Weissbach S, Rohrbach H, Weiler C, Spratt KF, Nerlich AG. Classification of age-related changes in lumbar intervertebral discs. Spine. 2002;27:2631-2644.

15. Kauppila LI. Ingrowth of blood vessels in disc degeneration. Angiographic and histological studies of cadaveric spines. J Bone Joint Surg Am. 1995; 77:26-31

16. Kemp HB, Jackson JW, Jeremiah JD, Hall AJ. Pyogenic infections occurring primarily in intervertebral discs. J Bone Joint Surg Br. 1973;55:698-714.

17. Tanigawa N, Akagi S, Kato Y, Sasai K, Saito T, Iida H. Vertebral osteomyelitis of the cervical spine. Seikei-Saigai Geka. (Orthopaedic Surgery and Traumatology). 2003;46:767-774. Japanese.

18. Saiga M, Kawai S. Treatment from the viewpoint of clinical features of cervical purulent spondylitis. Mon Book Orthop. 1996;9:37-41. Japanese.
International Medical Case Reports Journal

\section{Publish your work in this journal}

The International Medical Case Reports Journal is an international, peer-reviewed open-access journal publishing original case reports from all medical specialties. Previously unpublished medical posters are also accepted relating to any area of clinical or preclinical science. Submissions should not normally exceed 2,000 words or

\section{Dovepress}

4 published pages including figures, diagrams and references. The manuscript management system is completely online and includes a very quick and fair peer-review system, which is all easy to use. Visit $\mathrm{http}: / / \mathrm{www}$.dovepress.com/testimonials.php to read real quotes from published authors. 